\title{
ethic a \\ KARL-OTTO APEL: A PRAGMÁTICA TRANSCENDENTAL ENQUANTO PROPOSTA DE UMA NOVA CONFIGURAÇÃO DA FILOSOFIA
}

\author{
KARL-OTTO APEL: THE TRANSCENDENTAL PRAGMATICS AS A \\ PROPOSAL FOR A NEW CONFIGURATION OF PHILOSOPHY
}

\section{MANFREDO ARAÚJO DE OLIVEIRA ${ }^{1}$}

(UFC/Brasil)

\begin{abstract}
RESUMO
A preocupação fundamental de K-O. Apel, diante de uma situação de crise da razão que leva à negação da filosofia, é articular um novo projeto da filosofia enquanto tal, a Pragmática Transcendental, que levanta a pretensão de articular uma profunda reformulação do projeto transcendental clássico, elaborado por Kant, a partir da reviravolta linguístico-pragmática do século XX. Apel articula a filosofia enquanto autorreflexão sobre os pressupostos necessários e irrecusáveis da atividade de argumentar enquanto tal como a nova forma de "Prima Philosophia". O artigo procura mostrar que a Pragmática Transcendental, mesmo com sua reformulação pragmática do pensamento transcendental, conservou sua insuficiência ontológica e metafísica.

Palavras-chave: Filosofia Transcendental; Fundamentação última; Reviravolta Linguístico-pragmática; Argumentação.

ABSTRACT

Karl-Otto Apel,s fundamental concern, in the face of a crisis of reason that leads to the negation of philosophy, is to articulate a new philosophy project as such, the transcendental Pragmatics, which raises the pretension of articulating a profound reformulation of the classic transcendental project, elaborated by Kant, from the linguistic-pragmatic turn of the $20^{\text {th }}$ century. Apel articulates philosophy as self-reflection on the necessary and irrefutable presuppositions of the activity of arguing as such as the new forma of "Prima Philosophy". The article tries to show that transcendental pragmatics, even with its pragmatic reformulation of transcendental thought, retained its ontological and metaphysical insufficiency.
\end{abstract}

Keywords: Transcendental Philosophy; Ultimate Foundation; Linguisticpragmatic Turn; Argumentation.

\section{A) A Pragmática transcendental como nova proposta de filosofia}

Que está em jogo fundamentalmente no pensamento de K-O. Apel? Como se articula seu objetivo central em filosofia? A própria estruturação da 
filosofia enquanto tal, seu status específico no seio dos diferentes saberes. Essa reconstrução para ele é absolutamente decisiva em virtude da situação atual da filosofia que se caracteriza pelo fato de que tendências fundamentais da filosofia vigente põem em questão não simplesmente essa ou aquela tese filosófica, mas a filosofia enquanto tal, sua razão de ser. A historificação radical da razão que inseriu o sujeito do conhecimento na história, no mundo vivido histórico e social como tendência de fundo, por um lado, trouxe horizontes novos e questionou paradigmas que se julgavam inquestionáveis, por outro lado, porém, foi marcada por uma tendência à autodestruição da razão através de um relativismo generalizado que ameaça destruir os fundamentos da teoria e da ação do ser humano no mundo.

Essa posição inviabiliza qualquer tentativa ir de além do simplesmente contingente, mutável, condicionado, permanentemente passível de revisão e, portanto, descartável o que significa dizer que essa situação constitui um enorme desafio à filosofia. Assim, um fundamento seguro não constitui mais um objetivo que tenha sentido, consequentemente mudam as tarefas da filosofia. A primeira delas é a renúncia a ser o "Tribunal da Razão Pura" que julga todas as outras pretensões culturais. Ela não pode escapar do falibilismo radical que destrói todas as ilusões (ALBERT, 1975, 118 ss.): não há garantias definitivas. Em última instância está em curso uma crise da razão como instância de julgamento que conduz a uma "destranscendentalização" do pensar como o único caminho válido de superação do paradigma metafísico que nem a filosofia transcendental de Kant nem Hegel conseguiram efetivar (APEL, 1993b, 322).

Por outro lado, há hoje a hegemonia do saber especializado das ciências particulares sem que se possa determinar o lugar específico de cada um no todo já que a totalidade é inatingível. Faz-se hegemônica uma espécie de sistema de complementaridade entre existencialismosubjetivista-irracionalista e positivismo cientificista como as notas dominantes de nossa situação histórica (CARMO, 2011, 50 ss.). A consequência é que não temos hoje referenciais últimos. Para Apel, essa crise da razão é o problema fundamental que ele pretende enfrentar (APEL, 1988, 23 ss.).

A questão de fundo é: qual a especificidade de uma teoria filosófica? Esta questão é decisiva numa civilização em que a hegemonia teórica é das ciências. Que pretende, então a filosofia? Qual sua especificidade enquanto teoria? A nova proposta vai ser atingida através de sua diferenciação com as grandes propostas já elaboradas na tradição. Apel vai trabalhar esses paradigmas de filosofia a partir precisamente de seu status de teoria. Para expressar com clareza seu objetivo básico de articular um novo paradigma 
de filosofia ele vai usar para caracterizar os paradigmas fundamentais da tradição a expressão usada por Aristóteles para designar aquela dimensão da filosofia que era pressuposta por todas as outras: Prima Philosophia (APEL, 1993a, 170 ss.).

Para Apel a questão fundamental é que a filosofia, em contraposição ao conhecimento quotidiano e ao conhecimento das ciências, tem a ver com o conhecimento dos "pressupostos" destes conhecimentos, ou seja, seu específico é o "A priori". No fundo, é a questão da "mediação" negada pelo "empirismo". Ele distingue aqui duas propostas básicas na tradição e vai propor sua posição como alternativa de Prima Philosophia (APEL, 1975b, 32-61). Ele entende estas três posições não como uma simples sucessão incomensurável de paradigmas, mas como "suprassunção" [Aufhebung] no sentido de Hegel dos paradigmas anteriores através da radicalização da reflexão crítica.

1)A posição "metafísica ontológica", cuja temática fundamental é o ente enquanto ente, ou seja, ela "faz a pergunta sobre o porquê do mundo em sua totalidade, inclusive do homem como sujeito do conhecimento" (APEL, 1993b, 320), no entanto, para ele falta a essa posição qualquer reflexão sobre as condições de possibilidade de um tal perguntar o que significa dizer que aqui há uma falta fundamental: "a falta capital da metafísica que ela compartilha com o pensamento mítico: que ela somente é capaz de sugerir sempre uma fundamentação última de caráter dogmático" (APEL, 1993b, 306). Com Tugendhat $(1976,29)$, pode-se dizer que a característica fundamental é que, em contraposição a todo tipo de empirismo, essa posição reconhece a dimensão fundamental dos pressupostos só que seu acesso a essa esfera não ocorre via reflexão. É justamente isso que justifica que estes pressupostos sejam denominados na tradição de "princípios conhecidos por si mesmos" [principia per nota]. O conhecimento desses princípios se dá através de que se pode chamar de um "ver espiritual" que por Platão e Aristóteles foi chamado de "nous", em latim, foi traduzido por "intuitus", "visão", "intuição" que é um acesso imediato à esfera dos pressupostos.

O objeto da metafísica ontológica é o "ente enquanto ente" e seu conhecimento pressupõe a intuição dos pressupostos. Ao lado do conhecimento intuitivo dos princípios há o conhecimento dos diferentes entes do mundo que se faz através da "dedução", ou seja, por inferência ou derivação de algo de alguma coisa diferente de tal forma que para a metafísica todo conhecimento, além da intuição dos princípios, é dedutivo. Essa tese para Apel caracterizou não só a metafísica ontológica da tradição, mas também as ciências modernas. Em virtude, então, de uma falha na estrutura lógica da fundamentação, a metafísica racional é presa inevitável 
do Trilema de Münchhausen articulado por H. Albert (1968) que mostra a impossibilidade de uma fundamentação última nessa concepção de fundamentação.

O Trilema de Münchhausen apresenta a possibilidade de três tipos de fundamentação enquanto dedução: primeiro, é a busca de fundamentação para as premissas usadas na dedução o que desemboca num regresso ao infinito, portanto, nenhuma fundamentação última; segundo, é o procedimento de fundamentação que recorre a premissas elas próprias carentes de fundamentação, portanto, um círculo lógico; terceiro, a suspensão arbitrária em um determinado ponto do processo de fundamentação o que significa assunção de uma posição dogmática.

Apel entende a metafísica ontológica como "a disciplina especulativa das hipóteses globais" (APEL, 1976c) o que leva à conclusão de que "a metafísica tradicional ontológica e a moderna ciência hipotética têm como pressuposto a mesma estrutura de fundamentação, não podendo por isso oferecer nenhuma fundamentação última" (APEL, 1993b, 307).

2)Para Apel, foi Kant o articulador do segundo modelo da Prima Philosophia na medida em que, negando qualquer intuição intelectual, supera a "ingenuidade" de um conhecimento evidente de princípios e, assim, de um conhecimento sem qualquer mediação. A primeira característica do novo modelo é a tematização da "mediação irrecusável" de todo conhecimento objetivo da experiência ( $\mathrm{KrV}$, B 79, 80/A 55; B 81/A $56,57) .{ }^{2}$ Com isso, Kant articulou com precisão a tarefa específica de uma teoria filosófica em sua concepção: fundamentar nosso conhecimento de objetos da experiência, que nos são dados pela sensibilidade ( $\mathrm{rVV}$, B 33, 34/A 19,20), através da tematização do a priori que o torna possível, ou seja, explicitar as condições puras, a priori, de toda experiência possível, os conceitos que constituem as condições a priori de todo conhecimento da experiência (KrV, A 96).

Numa palavra, a tarefa básica da filosofia é a fundamentação do nosso conhecimento dos objetos da experiência através da tematização do a priori que os possibilita. Trata-se assim de demonstrar a "possibilidade" e a "validade" de nosso conhecimento empírico e para distinguir precisamente este tipo de conhecimento de nossos conhecimentos empíricos ele o denomina de "transcendental" (KrV, B 81/A 56,57). O que aqui é simplesmente decisivo é a tese de que filosofia, em contraposição às ciências, é, em sentido estrito, uma "postura reflexiva" que tem como objetivo explicitar os fundamentos do conhecimento e da ação válidos.

Enquanto fundamento da possibilidade e da validade de nossos conhecimentos $\mathrm{o}$ a priori transcendental se distingue, contudo, radicalmente de outros tipos de a priori como, por exemplo, o da 
matemática que significa apenas independência da experiência. Sua proposta consiste para Apel em tratar na "subjetividade" a questão das condições de possibilidade e validade dos conhecimentos empíricos através de uma "dedução transcendental", ou seja, de um procedimento de tematização das condições "subjetivas" necessárias de nossos conhecimentos e ações. A dedução transcendental constitui o cerne da proposta de Kant e ele entende aqui a palavra "dedução" no sentido utilizado pelos juristas de um procedimento que tem como objetivo demonstrar o direito ou a legitimidade de uma pretensão (KrV, B 116,117/A 84). A "consciência" emerge aqui como a "esfera transcendental", ou seja, das condições aprióricas. É, assim, uma autorreflexão da subjetividade transcendental que assume a função de fundamentação de todo conhecimento (APEL, 1993a, 171). Para Apel, E. Husserl foi o último clássico desse segundo paradigma.

A necessidade de um terceiro paradigma se radica numa proposta de superação das insuficiências da filosofia transcendental clássica que são para Apel basicamente três: a) É insustentável o caráter incognoscível da coisa em si: nosso conhecimento a priori "só concerne os fenômenos, deixando, ao contrário a coisa em si mesma de lado como real para si, mas não conhecida por nós" (KrV, B XX,XXI); b) Kant não compreendeu a mediação linguística na constituição do conhecimento; c) Consequentemente, não considerou a dimensão da intersubjetividade como irrecusável (KUHLMANN, 1985, 13 ss.). Por isso Apel vai concentrar-se em duas questões básicas: a) O conhecimento de princípios não pode ocorrer através de dedução (o Trilema), mas por "reflexão" sobre as condições necessárias de uma argumentação com sentido; b) A consciência já é sempre linguisticamente mediada: a linguagem é a nova esfera transcendental. A dimensão da pragmática, esquecida na primeira fase da reviravolta linguística, é simplesmente decisiva para a elaboração da estrutura específica da demonstração dos princípios. A argumentação não é, então,uma produção de um sujeito isolado, mas deve ser entendida com atuação de participantes de uma comunidade de comunicação que cooperam entre si.

3) O terceiro paradigma é a proposta de Apel que ele denomina de "Pragmática Transcendental" que se articula a partir de uma profunda transformação da filosofia transcendental do segundo paradigma, conservando, porém, o sentido de tematização da aprioridade como a característica básica da filosofia em relação aos outros saberes. W. Kuhlmann (1985, 305-307) considera que a reviravolta fundamental da Pragmática Transcendental em relação à proposta do segundo paradigma se deu, em primeiro lugar, a partir do enfrentamento das objeções feitas 
ao projeto de Kant. São basicamente três objeções centrais: a) A primeira objeção diz respeito tanto à base do argumento quanto ao procedimento como um todo. A justificação dos juízos sintéticos a priori através da referência a uma "experiência confiável" não basta basicamente por duas razões: primeiro porque um cético radical pode sempre pôr em questão a confiabilidade da experiência, segundo porque o desenvolvimento da física moderna põe em questão esse conceito de experiência de modo que se torna questionável a base do argumento.

R. Kroner (1961, vol. 1, 73) explicitou com precisão a problemática da "circularidade" no procedimento kantiano de que o próprio Kant teve consciência (KrV, B 764, 765/A 736, 737; B 766/A 738): "Não incorre a dedução num círculo, quando ela, para fundamentar a experiência, recorre ao fato da experiência"?, ou seja, Kant toma como fundamento da demonstração da validade das sentenças sintéticas a priori a possibilidade da experiência, quando são justamente aquelas sentenças que possibilitam a experiência (KUHLMANN, 1985, 21); b) A irreflexibilidade do procedimento kantiano que torna o procedimento kantiano vulnerável à objeção do cético; c) A terceira objeção diz respeito à consequência mais importante do procedimento kantiano: a tese da coisa em si incognoscível.

Para Kuhlmann, esse problema manifesta a falha fundamental do modelo de filosofia transcendental articulado por Kant, porque mostra que ele não captou o específico de um pensamento transcendental. Kant não distinguiu entre uma "postura teorética" que trata de objetos e uma "postura reflexiva" que não trata de objetos. Por isso, quando ele trata da relação entre a subjetividade transcendental e o mundo dos objetos ele os trata como se fossem duas entidades do mundo. Ele não é capaz de compreender que o a priori de nenhuma forma é uma entidade que está diante de uma outra de tal modo que se possa perguntar sobre a conexão entre as duas entidades. Por essa razão a questão da coisa em si não tem o menor sentido no terceiro paradigma (KUHLMANN, 1985, 310-311).

Uma questão prévia é para Apel simplesmente decisiva: partindo-se do segundo paradigma se busca uma alternativa mais radical para a fundamentação última, ou seja, faz-se necessário repensar a própria estrutura da filosofia transcendental. Para a tradição empirista, as ciências modernas articularam com seu método o padrão de racionalidade: as únicas fontes seguras de conhecimento são a experiência e a observação. Dessa forma não tem o menor sentido a filosofia reivindicar algo distinto. Portanto, a única possibilidade de sobrevivência da filosofia em nossa civilização técnico-científica é assumir essa nova racionalidade. No entanto, a confiabilidade e a segurança desse método foram radicalmente questionadas e o falibilismo ilimitado é sua expressão suprema. 
No contexto do falibilismo generalizado surge uma questão: como explicar o processo científico de conhecimento? Como um simples processo natural de envelhecimento de teorias? Se não queremos assumir a posição de Feyerabend (1976) do [anything goes] de tal modo que não seja mais possível distinguir entre teorias e contos de fada e se pretendermos compreender a ciência e seu processo como uma empresa racional, temos que que, pelo menos minimamente, compreender o que significa pretensão de verdade o que significa dizer que o cerne é a questão da fundamentação.

A questão crucial neste contexto é: tudo se reduz a hipóteses falsificáveis? O falibilismo sem limites constitui a palavra final? Possui a filosofia, consequentemente o mesmo ideal metodológico das ciências da natureza hoje hegemonicamente considerado o paradigma de racionalidade? (APEL, 1976a, 12 ss.). O racionalismo crítico afirma que o princípio do falibilismo se aplica também à filosofia de modo que, em última instância, estamos diante não de uma fundamentação última, mas de uma "decisão última" a respeito da normatividade de nossas questões teóricas e práticas.

Apel em primeiro lugar pergunta qual é a situação das pressuposições de evidências que o falibilismo ilimitado deve pressupor para poder ser compreendido. Para ele, sem uma fundamentação última o próprio falibilismo não se sustenta.

Nisso [...] consiste a indispensável fundamentação filosófica última do princípio do falibilismo. Como necessária [...] particularmente porque a abertura não-dogmática e a liberdade de violência do discurso argumentativo, como condição normativa de possibilidade de crítica e possível falsificação de hipóteses, deve ser garantida (APEL, 1993b, 313).

Trata-se para ele aqui, na realidade, de garantir o maior espaço possível para o falibilismo na ciência moderna e isso foi feito até agora através da reflexão sobre os pressupostos de uma argumentação atual e precisamente também do crítico da argumentação. Nesse sentido se perguntou pelas necessárias condições de possibilidade do princípio do falibilismo o que conduziu ao princípio do discurso e ao caráter irrecusável de pressuposições de existência e de regras do discurso argumentativo. 0 critério último do caráter incontestável das pressuposições é a "autocontradição pragmática" ou performativa: contesto com argumentos que eu eu esteja argumentando. ${ }^{3}$

A autocontradição pragmática se compreende a partir da teoria dos atos de fala que afirma uma dupla estrutura da fala: o aspecto proposicional 
(dimensão semântica) e o aspecto performativo (dimensão pragmática). Böhler distingue, então, dois tipos de inconsistência: a inconsistência "lógica" que consiste numa falha no procedimento de derivação de sentenças a partir de outras e inconsistência "pragmática" que ocorre no seio de uma ação de argumentação, por exemplo, quando o cético afirma que não há verdade. A contradição aqui se dá entre o conteúdo proposicional (negação da verdade) e ação efetivada (pretensão de verdade) (BÖHLER, 1985, 371 ss.). Na fundamentação última da pragmática transcendental trata-se de "uma fundamentação discursivoreflexiva de evidências de que não se pode duvidar sem autocontradição (inconsistência pragmática) e que não podem ser deduzidas sem "petitio principii" (DE OLIVEIRA, 1993, 65). Aqui está para Apel

o critério de teste que distingue o específico método da fundamentação filosófica última que reflete sobre as condições de validade do argumentar de qualquer exame empírico de hipóteses falíveis da ciência e de uma metafísica concebida como ciência de hipóteses globais" (APEL, 1993b, 316).

Numa palavra, o ceticismo moderno é para a filosofia uma oportunidade extraordinária para uma tomada de consciência de si mesma e para a determinação de sua tarefa específica em contraposição a outros tipos de discurso. Para Apel, a grande distinção da metafísica ontológica, da ciência moderna e do Trilema de Münchhausen do que se articula na posição alternativa de fundamentação é que nesses procedimentos se entende fundamentação enquanto dedução de um algo de outro algo: "No estrito sentido de prova apodítica esta definição se refere à dedução lógica e matemática" (APEL, 1993b, 316), que estruturalmente pode alcançar apenas uma "validade hipotética".

O método de fundamentação filosófica apresentado por Apel significa uma mudança radical de paradigma na compreensão do que seja fundamentação e por isso difere radicalmente da concepção de fundamentação enquanto derivação na medida em que se trata na filosofia de uma "reflexão estrita" sobre as condições de validade da argumentação que não é vulnerável ao regresso ao infinito, como é o caso na derivação, uma vez que não é possível contestá-la sem autocontradição performativa, ou seja, quando o cético duvida dos pressupostos irrecusáveis da argumentação, ele se contradiz a si mesmo.

O falante em cada ato de fala se relaciona reflexivamente (estritamente) com suas próprias ações linguísticas atuais e com seus proferimentos e não apenas com um conteúdo proposicional afirmado. Isso 
implica fazer uma passagem de uma consideração apenas sintáticosemântica para uma consideração pragmática da linguagem. Foi através dessa concepção da "dupla estrutura da fala" que a pragmática transcendental pode justificar a reflexão transcendental que havia sido considerada inviável em virtude da objeção de B. Russell contra expressões linguísticas autorreflexivas por conduzirem inevitavelmente a antinomias e sua sugestão de as substituir por uma teoria dos tipos (RUSSELL, 1908, 222-262). Sem essa mudança radical de postura é impossível uma demonstração filosófica o que teria uma consequência inaceitável: a compreensão da filosofia como um saber de objetos.

Apel reconhece que o método da fundamentação reflexiva já está há tempo presente na tradição filosófica ocidental (Platão, Aristóteles, antiga refutação dos céticos sobretudo em Agostinho e na modernidade em Descartes) como tentativa de superação da metafísica através da reflexão sobre as condições de possibilidade e de validade intersubjetiva. Na modernidade, essa tendência crítica de reflexão assumiu primeiro a forma de uma "filosofia da consciência" que agora passa por uma transformação pragmático-linguística enquanto reflexão sobre as condições de validade intersubjetiva da argumentação (APEL, 1993b, 320).

O específico desse terceiro paradigma é a compreensão de que as evidências indispensáveis da experiência já são evidências interpretadas linguisticamente e por isso não a síntese da minha apercepção, mas somente a síntese última possível da interpretação capaz de consenso pode garantir a verdade enquanto validade intersubjetiva (APEL, 1987, 116211). Isso se fez possível quando se percebeu que o conhecimento pressupõe irrecusavelmente uma mediação linguística:

Desde Peirce e Wittgenstein, tornou-se sempre mais claro de que não é possível pensar um sujeito solitário e autárquico, por causa da interpretação intersubjetivamente válida por causa da dependência da linguagem de todo pensar intersubjetivamente válido de algo enquanto algo (APEL, 1993b, 321).

Kuhlmann (1985, 76 ss.) explicitou a estrutura própria do argumento da filosofia pragmática transcendental distinguindo a posição teorética de uma reflexão estrita. A "postura teorética" é aquela em que o saber está concentrado no objeto, portanto, é um saber objetal em que o sujeito não tem consciência de sua práxis enquanto cognoscente de objetos. O que importa aqui é exclusivamente o objeto. A "reflexão estrita" é um saber explícito sempre duplo: é um saber de um tema qualquer e igualmente um saber do sujeito que conhece esse tema. A diferença entre o saber das 
ciências e saber da filosofia é que a filosofia exige uma mudança radical de postura em relação ao saber objetal: ela é essencialmente uma reflexão estrita em que se reflete sobre o que alguém, na discussão, pressupõe como condição de possibilidade da própria discussão.

A "fórmula" de fundamentação última para Kuhlmann vale precisamente dos pressupostos irrecusáveis da argumentação:

aquilo que não se pode recusar sem autocontradição atual, contra cujo reconhecimento não se pode decidir sem autocontradição, aquilo que não pode ser fundamentado através de derivação sem petitio principii, isto nos é ineliminável, na argumentação e enquanto tal. Isto vale absolutamente como seguro e pode ser tomado com base incondicional de outras fundamentações (condicionadas) (KUHLMANN, 1985, 23).

A questão de fundo aqui é a demonstração de uma evidência que é inabalável por qualquer dúvida justamente por ser o pressuposto irrecusável da própria dúvida e filosofia é exatamente isto, ou seja, uma reflexão sobre o que a dúvida necessariamente pressupõe para poder efetivar-se.

Consequentemente, o objetivo da pragmática transcendental é tematizar a situação da argumentação não numa postura teorética, isto é, como saber objetal, mas enquanto condição irrecusável da validade da ação linguística o que só é possível numa postura reflexiva. No nível do saber teorético, por definição, é impossível uma fundamentação última e se aplica plenamente o Trilema de Münchhausen porque está em jogo sempre aqui uma fundamentação por derivação. A partir daqui se explica porque uma questão absolutamente central no pensamento de Apel é explicitar a "estrutura lógica" do argumento de fundamentação última. ${ }^{4}$ Seu esforço teórico visa responder à pergunta: como é possível uma reflexão crítica sobre as condições de validade da argumentação. A conclusão manifesta com precisão o projeto apeliano de filosofia: filosofia não fornece qualquer "explicação ontológico-cosmológica do mundo, mas apenas uma autocertificação da razão argumentativa" (APEL, 1993b, 317).

Com isso, Apel retoma as intuições fundamentais do segundo paradigma: filosofia não é conhecimento do mundo, mas antes sua tarefa específica é enfrentar a questão da fundamentação do nosso conhecimento dos objetos do mundo, portanto, sua esfera temática se situa no "A priori" que possibilita e legitima nosso conhecimento dos objetos. Assim, filosofia não é conhecimento de objetos como as ciências, mas sua questão específica é a "questão da validade" de nossos conhecimentos, ou seja, 
filosofia tem a ver fundamentalmente com fundamentação última. A radicalização do segundo paradigma se mostra claramente no fato de que a argumentação é certamente a única em relação à qual não se pode relativizar a validade das respostas uma vez que sempre que se levanta a validade já se faz presente a argumentação, ou seja, o ato de argumentar e seus pressupostos necessários são incontornáveis:

nada pode ser reivindicado como válido a não ser que possa ser fundamentado racionalmente mediante argumentos. Temos aqui um imperativo categórico dialógico que prescreve resolver todas as pretensões de validade da razão argumentativamente (HERRERO, 1991, 56).

A argumentação é, assim, o específico da razão humana, a esfera que diz respeito à questão da validade, que é aqui situada não numa filosofia da consciência, mas na esfera da linguagem, ou seja, a partir de uma teoria da comunicação intersubjetiva simbolicamente mediada de modo que o sujeito transcendental de Kant é agora a "comunidade dos argumentantes"5 o que significa uma superação radical do solipsismo filosófico e, assim, o quadro da intersubjetividade passa ao primeiro plano. Isso significa dizer que a afirmação de uma proposição, de uma tese etc. ocorre sempre num discurso público. Quem participa desse discurso já sempre aceitou pressupostos irrecusáveis, cuja negação implica em autocontradição performativa. A filosofia tem precisamente a ver com a tematização dos pressupostos necessários desse discurso. Daí a tese fundamental de Apel:

uma fundamentação última não só é possível, mas absolutamente inevitável. Não é possível recuar para além da dimensão pública de um discurso teórico; desse modo tampouco é possível rever as pressuposições nela contidas (PUNTEL, 2008, 72).

Apel exprime a transformação afirmando que se trata em seu paradigma de uma fundamentação numa filosofia pós-metafísica, crítica e falibilista. Assim, na perspectiva de uma reformulação do modelo kantiano, ele vai acentuar que o núcleo central da atividade filosófica vai consistir em ir além de fundamentações condicionadas $e$, consequentemente, relativizáveis para uma demonstração não condicionada e, portanto, não relativizável. Neste sentido para Apel se deve dizer que a filosofia é uma reflexão sobre as pretensões universais irrecusáveis de validade que fazem parte do argumentar. Dessa forma, filosofia é reflexão sobre os 
pressupostos não contingentes do conhecimento válido do contingente. Como foi possível essa reformulação?

O pressuposto decisivo aqui é a substituição da "consciência" pela "linguagem" enquanto esfera transcendental. Apel considera Peirce o primeiro a articular uma transformação semiótica da filosofia transcendental de Kant (APEL, 1975a). Para ele, a "filosofia da linguagem" assume, então, a função da filosofia transcendental no sentido de Kant, isto é, assume igualmente a função de Prima Philosophia. O ponto decisivo, então, dessa transformação enquanto passagem de uma crítica do conhecimento enquanto análise da consciência para uma crítica do conhecimento enquanto análise da linguagem está em que o problema da validade da verdade não é mais o da evidência ou certeza para uma consciência solitária no sentido de Descartes, mas também não mais o da validade objetiva(e enquanto tal intersubjetiva) para a consciência enquanto tal no sentido de Kant, mas originariamente o da formação de um "consenso intersubjetivo" na base de uma compreensão linguísticoargumentativa, onde todas as evidências subjetivas são situadas e julgadas e eventualmente corrigidas.

A argumentação é um processo intersubjetivo que se efetiva em atos de fala. Com isso a argumentação pressupõe uma comunidade real (o "a priori da facticidade") e uma comunidade ideal de comunicação (o "a priori do discurso") e isso gera, do ponto de visar ético, os dois deveres fundamentais: a sobrevivência da humanidade e nela a realização da comunidade ideal. A história humana se constitui enquanto tensão entre as duas comunidades (HÖSLE, 2013, 293). Isso significa que a filosofia transcendental não pode mais centrar-se num "sujeito isolado" que se contrapõe ao mundo dos objetos e dos outros sujeitos. Produções cognitivas são sempre produções comunicativas que só podem ser objeto de consideração em relação a uma comunidade de comunicação.

Numa palavra, muda-se aqui radicalmente a concepção de conhecimento: agora não se trata mais de princípios e produções de uma consciência isolada, mas antes de competências, produções, regras, pressupostos fundantes para parceiros de uma comunidade de comunicação simbolicamente mediada. Há, assim, mútua imbricação entre conhecimento e comunicação. Portanto, conhecimento é uma ação mediada por signos, uma tese já articulada por Peirce, pois para ele um sinal [Zeichen] é algo tridimensional: "é algo que designa algo para alguém". Isto é o que se denominou "realismo crítico de sentido" como a única forma de ontologia aceitável. Nessa direção, a pragmática transcendental vai substituir a noção de fenômeno e de coisa em si estruturalmente incognoscível da filosofia 
kantiana pela ideia de Peirce do real enquanto em princípio cognoscível e o de fato conhecido aqui e agora.

Há aqui uma continuidade entre os dois paradigmas na tese de que filosofia é reflexão sobre a possibilidade e validade do conhecimento, mas diferença fundamental já que de agora em diante a linguagem é o tema e, sobretudo, o medium da filosofia transcendental (APEL, 1976b, 311 ss.). Essa diferença traz consequências fundamentais e decisivas para a articulação de terceiro paradigma da Philosophia Prima: o A priori não é mais a condição necessária da "experiência", que o cético sempre pode recusar, mas é condição necessária da validade da "argumentação" com sentido que o cético não pode recusar sem incorrer numa autocontradição performativa.

Dessa forma, a "reviravolta linguística", de nenhum modo, pode ser interpretada, como o fez $\mathrm{H}$. Krings (1978, 57-75), como um retorno a um a posteriori enquanto objeto de uma ciência, pois o que aqui está em jogo não é um objeto, mas a tematização dos componentes inelimináveis, isto é, aprióricos e necessários de toda ação linguística através de que conhecemos os objetos. A linguagem não é na filosofia um novo tema, mas o pressuposto necessário de todo conhecimento e de toda ação humanos. A filosofia da linguagem se torna, então, uma reflexão sobre as condições linguísticas da possibilidade e validade do conhecimento e da ação e, assim, toma o lugar da teoria do conhecimento do paradigma anterior. A linguagem, portanto, aqui não é simplesmente um objeto de investigação, mas condição de possibilidade e validade do conhecimento de qualquer objeto, uma postura que não existe na filosofia analítica da linguagem de hoje que procura deslegitimar essa problemática (APEL, 1976b, 318 ss.).

\section{B) Elementos de diálogo com a Pragmática Transcendental}

K-O. Apel parte de uma situação histórica: nosso contexto filosófico atual que para ele significa de fato a negação radical da filosofia em sua diferença de outros saberes. Segundo sua leitura da tradição e sua "superação, ele afirma que a filosofia é fundamentalmente "fundamentação última reflexiva", ou seja, filosofia tem a ver essencialmente com a fundamentação de si mesma e de todo saber, essa constitui sua tarefa específica e exclusiva. ${ }^{6}$ A questão primeira aqui é que o conceito de fundamentação aparece sem que aqui seja minimamente tematizado o que ele pressupõe, pois qualquer resposta à questão vai pressupor, por exemplo, algo na esfera da lógica (em que lógica ela se radica?), da linguagem (nesse paradigma, a linguagem é um pressuposto absolutamente central), da teoria do conhecimento, de teoria enquanto tal, 
etc. Não há consideração alguma sobre os componentes constitutivos da linguagem (com que sintaxe, com que semântica, com que pragmática se trabalha?) (PUNTEL, 2008, 70).

A filosofia enquanto atividade teórica tem como objetivo a compreensão. Que é compreender? Levantar essa pergunta significa perguntar sobre os componentes irrecusáveis de uma teoria. Ao conjunto desses componentes se pode denominar de "quadro teórico". A primeira consequência a tirar daqui é que qualquer problemática trabalhada está implícita ou explicitamente situada num quadro teórico e só é compreensível relativo a ele. Revela-se, assim, que a pragmática transcendental tratou o problema da fundamentação sem explicitar seu quadro teórico. Compreender, então, emerge como a consideração de algo a partir da esfera das estruturas fundamentais da linguagem sem as quais nada se determina. Compreendemos sempre no seio de um determinado quadro teórico. A cada quadro estrutural pertencem, enquanto momentos constitutivos: uma lógica, uma sintaxe, uma semântica e uma ontologia porque esses são os componentes irrecusáveis de um quadro teórico enquanto componentes irrecusáveis da linguagem.

Por esta razão a primeira tarefa da filosofia é a investigação desta dimensão enquanto o quadro para a compreensão de qualquer realidade. $A$ dimensão do compreender pode ser denominada de "dimensão estrutural" entendendo-se "estrutura" (PUNTEL, 2008, 34) como uma conexão diferenciada e ordenada, respetivamente enquanto relação e ação recíproca de elementos de uma entidade ou de uma região ou de um processo.

Uma questão fundamental aqui, já que a linguagem é composta de sentenças, é a pergunta pelo tipo específico de sentenças que está em jogo na atividade teórica de que a filosofia é uma das formas. Trata-se na esfera da teoria daquilo que a tradição chamou de sentenças declarativas ou indicativas ou simplesmente sentenças teóricas. A estrutura dessas sentenças foi caracterizada por Wittgenstein no Tractatus (4.5): "...A forma proposicional geral é: as coisas estão assim". Numa palavra, uma sentença teórica é aquela que implícita ou explicitamente é antecedida pelo operador "é o caso que", ou seja, por um operador que indica que uma sentença teórica é uma sentença que não implica qualquer fator de restrição (PUNTEL, 2015, 30-31). Trata-se, então, de um operador teórico estritamente universal.

Ora, a formulação da filosofia transcendental de Kant é um exemplo claro de uma filosofia que implica um fator de restrição da sentença. Levando-se em consideração o paradigma articulado por Kant pode-se dizer que as sentenças teóricas transcendentais são estruturadas assim: "Da perspectiva da subjetividade transcendental é o caso que $p$ " o que significa 
que desse modo não se alcança a dimensão teórica genuinamente universal como é a pretensão de Kant (PUNTEL, 2008, 146 ss.). A pragmática transcendental conserva essa postura reformulando-a. Pode-se exprimir assim essa reformulação: "Da perspectiva da intersubjetividade transcendental é o caso que $\mathrm{p}$ ". Isso significa dizer que a pragmática transcendental levanta a pretensão de fundamentação da objetividade universal, mas seu operador é um fator de restrição o que impossibilita de atingir a universalidade pretendida.

O primeiro passo da argumentação aqui consiste em mostrar que no plano semântico está em jogo uma determinação puramente interna à linguagem o que constitui sua especificidade em relação aos dois planos anteriores, ou seja, ao plano de determinação do mundo da vida e ao plano pragmático. Neste plano o operador é: "É verdadeiro que" que não comporta referência a qualquer fator externo à linguagem (sujeito, ações, eventos, etc.). Numa palavra, trata-se aqui de um determinante puramente interno à linguagem o que significa dizer que o específico deste nível é precisamente que através do vocabulário semântico a própria linguagem se autodetermina, um elemento que não é tematizado no modelo apeliano.

A questão mais radical nesse contexto é que o Pragmatismo apeliano, na realidade, não pôs em questão o esquema de fundo do pensamento transcendental apesar de sua tese de uma mudança de paradigma em relação à filosofia da consciência. Trata-se da dicotomia fundamental entre pensar e ser rearticulada na leitura pragmática do transcendental por ele proposta enquanto dicotomia entre linguagem e mundo. $O$ que está em jogo aqui é uma problemática que concerne à estruturalidade imanente da teoria enquanto tal. Uma resposta a esta questão é condição elementar de possibilidade da própria atividade teórica em qualquer nível de sua efetivação. Todo e qualquer projeto teórico tem como incumbência básica compreender, conceituar, explicar ou articular um X determinado (PUNTEL, 2008, 205 ss.). O X tem a ver aqui com a "coisa", o "tema", o "conteúdo" da teoria, no caso específico da filosofia se trata da coisa da filosofia, a coisa do pensamento para usar uma expressão de Heidegger (HEIDEGGER, 1969).

Esta coisa da filosofia foi designada com diferentes expressões no curso de sua história: physis, realidade, ser, natureza, mundo, etc. 0 problema de fundo é: que significa compreender algo, questão que perpassa explícita ou implicitamente toda a história do pensamento filosófico ocidental. Pode-se de certa forma classificar as posições filosóficas a partir de sua compreensão da relação entre o "compreender" e "o que é compreendido" tomando como critério a resposta à pergunta se o compreender é determinado a partir do que é compreendido ou, ao 
contrário, o que é compreendido a partir do compreender. É improvável achar uma posição pura destas duas propostas, mas elas são muito determinantes para classificar as posições básicas, portanto, o tipo de filosofia articulado.

Ora, Apel não questiona o quadro teórico básico proposto por Kant e expresso na formulação famosa: "a filosofia transcendental não tem a ver tanto com os objetos, mas com nossa forma de conhecimento de objetos na medida em que ele deve ser possível a priori" (KrV, B: 26; A: 13): tratase aqui de tematizar demonstrativamente o próprio compreender como a esfera que estabelece a determinação do que é compreendido. Esta transformação de rumo efetivada na filosofia de Kant é o que E. Tugendhat (1976, 13-23) denominou "revolução reflexiva" do pensamento no sentido de que o objetivo da filosofia é fundamentar nossos conhecimentos empíricos e as normas de nossa ação por meio das estruturas do equipamento cognitivo de nossa subjetividade.

Este procedimento conduziu Kant à tese fundamental de que todo conhecimento é categorial, ou seja, o que nos é dado pela sensibilidade só pode ser constituído de forma universalmente valida como objeto através da mediação das categorias de nosso entendimento. Isto o autoriza a afirmar que o entendimento humano estatui leis para a natureza ( $\mathrm{KrV}, \mathrm{B}$ : 134), ou seja, as leis não constituem propriedades dos fenômenos, mas exprimem somente sua relação ao sujeito, cujo ponto máximo é justamente o entendimento ( $\mathrm{KrV}, \mathrm{B}: 164$ ).

A Filosofia Transcendental, a nova postura teórica, não compartilha mais a pretensão da metafísica da tradição de fazer afirmações aprióricas sobre a realidade em si mesma ${ }^{7}$, sua constituição intrínseca, mas sua tarefa nova consiste, como diz Apel, na reconstrução das condições universais e necessárias sob as quais algo pode tornar-se objeto do conhecimento. Só na experiência está a verdade, portanto, tudo que nos pode ser dado como objeto tem que ser dado na intuição sensível. Por esta razão a filosofia se restringe a demonstrar a determinidade apriórica dos objetos enquanto se manifestam a nós e não em si mesmos e é neste sentido que Kant é considerado o primeiro antirrealista moderno. ${ }^{8}$ Assim, o conhecimento de coisas em si mesmas a partir do entendimento puro não passa de uma ilusão.

O desfecho desta indagação é para Kant que no nível teórico o conhecimento humano é restrito ao mundo fenomênico ( $K r V, B: X I X-X X)$, atestando-se de forma indiscutível o abismo entre o subjetivo e o objetivo, entre a subjetividade e as coisas em si mesmas, inatingíveis por nossas faculdades cognitivas (KrV, B: XIX), portanto, entre a dimensão do sujeito 
e a dimensão da realidade de tal modo tudo o que é conceitual pertence aqui ao polo do sujeito, ao compreender.

Com isto emerge de fato uma tese fundamental alternativa à tese da tradição greco-medieval e se pode dizer que esta tese da heterogeneidade radical entre o subjetivo e o objetivo começou a articular-se com o pensamento do nominalismo do fim da Idade Média e constitui o grande legado da filosofia transcendental:

De fato, essa afirmação de heterogeneidade [...] deve ser creditada ao movimento nominalista medieval. Foram esses nominalistas medievais, ciosos da necessidade de uma crítica ao ideal grego de racionalidade, que estabeleceram uma cisão entre razão e experiência. Para eles, invertendo o lema hegeliano, o racional não é real e o real não é racional (FENATI, 1998, 170).

Trata-se, portanto, da cesura, da separação, da dicotomia, entre a dimensão do pensar e a do ser, a do sujeito e a do objeto, a da teoria e a do mundo, do universo, do ser em seu todo que marcará hegemonicamente todo o pensamento moderno até hoje. Esta postura impossibilita uma visão unitária do real de modo que o objetivo de um conhecimento capaz de articular as interconexões últimas de toda a realidade se vai chocar sempre com o obstáculo intransponível de um dualismo irrevogável: "Limitados pelo pensamento, ou, mais modernamente, pela linguagem, estamos sempre às voltas com mundos criados por nós" (FENATI, 1998, 171).

O sentido da problemática transcendental é, assim, assumido por Apel e radicalizado; o que ele propriamente pretende superar através da reviravolta linguística é o que ele denomina o "conceito mentalístico" fundamental de autorreflexão o que significa para ele fazer uma leitura pragmática da esfera transcendental. Nesse sentido se articula sua tese fundamental: a filosofia não é uma "explicação ontológico-cosmológica do mundo, mas apenas uma autocertificação da razão argumentativa" (APEL, 1993b, 317).

A questão central aqui é o rebaixamento da semântica a segundo plano quando não a esquecimento total o que conduz ao abandono da ontologia. A primeira questão aqui é a compreensão de que as estruturas fundamentais de conteúdo do quadro estrutural só podem ser articuladas linguisticamente, ou seja, os conteúdos conceituais não existem sem articulação linguística de tal forma que não se pode separar um do outro a não ser que se admita uma relação puramente extrínseca entre ambos o que levanta o enorme problema de saber como é possível que a articulação linguística expresse justamente os conteúdos conceituais. Ora se a 
linguagem é condição de articulação dos conteúdos e na linguagem a dimensão semântica é condição de inteligibilidade da dimensão pragmática, então a tematização das estruturas semânticas é condição de inteligibilidade dos conteúdos conceituais. As estruturas semânticas e as estruturas ontológicas se implicam mutuamente.

É precisamente isto que expressa McDowell $(2005,64)$ com suas afirmações muito fortes contra a postura de toda a filosofia moderna: não há nenhum abismo ontológico entre o tipo de coisa que se pode significar, ou de modo geral, o tipo de coisa que se pode pensar, e o tipo de coisa que é o caso. Quando nosso pensamento é verdadeiro, o que pensamos é o que é o caso, pois na medida em que o mundo é algo que é o caso, não há abismo algum entre o pensamento enquanto tal e o mundo. Pensamento pode significar o "ato de pensar", mas pode significar também o "conteúdo" deste ato, aquilo que se pensa.

Então, quando se fala de uma realidade independente, temos a ver com uma realidade independente do ato de pensar e de julgar, mas não com algo que esteja fora do conteúdo pensável. O objeto da experiência, o estado de coisas experimentado como existindo, é entendido como uma parte de uma totalidade pensável. Assim, o fato de a experiência ser passiva nos assegura um constrangimento externo de que precisamos racionalmente. $O$ constrangimento vem de fora do ato de pensar, mas não de fora do que é pensável. Somos um animal que vive sua vida em relações cognitivas e práticas com o mundo (McDOWELL, 1998, 289).

Na realidade, a superação deste abismo entre pensar e ser é um pressuposto irrecusável de todo e qualquer empreendimento teórico científico ou filosófico uma vez que enquanto tal um empreendimento teórico só é possível na medida em que se pressupõe que aquilo de que trata, ou seja, um recorte da realidade ou a realidade em seu todo, é captável apreensível, articulável, expressável. Ora se o universo é expressável, então, todo e qualquer abismo de antemão já está superado o que significa dizer que os dois polos são essencialmente relacionados um ao outro, "eles representam apenas dois níveis secundários ou relativos de uma relação em que ambos remetem um ao outro e em que ambos desde o início já estiveram conectados e unidos" (PUNTEL, 2008, 22).

O problema fundamental aqui não é reconhecer a diferenciação, mas interpretá-la como dicotomia, como cesura insuperável. É justamente nesta relação original que a diferenciação pode ser compreendida. A expressão literária desta compreensão é precisamente o critério de teoricidade o que nos revela que Apel não compreendendo o caráter ineliminável da ontologia em última instância não tematizou em toda a sua abrangência o caráter específico da teoria enquanto tal. 
O objetivo fundamental da Pragmática Transcendental é articular um novo paradigma para a filosofia enquanto tal reformulando o paradigma da filosofia transcendental de Kant através da passagem de uma filosofia da consciência para uma filosofia da linguagem como esfera transcendental. Só que, não tendo feito uma análise dos componentes necessários da linguagem (sintaxe, lógica, semântica, ontologia, pragmática), ele vai concentrar-se exclusivamente na problemática do tipo de fundamentação que está em jogo na filosofia. O resultado é a redução da filosofia a uma pura reflexão sobre o a priori abstraindo de tudo mais como pergunta específica das ciências.

Kuhlmann articulou muito bem essa posição tratando, como vimos, o problema da "superação da coisa em si" como incognoscível no paradigma da filosofia transcendental em Kant o que, segundo ele, é uma questão que não tem absolutamente sentido porque isso seria uma pergunta por objeto que não compete à filosofia. "Kant não distinguiu, afirma ele, entre uma "postura teorética" que trata de objetos e uma "postura reflexiva" que não trata de objetos. Por isso, quando ele trata da relação entre a subjetividade transcendental e o mundo dos objetos, ele os trata como se fossem duas entidades do mundo. Ele não foi capaz de compreender que o a priori de nenhuma forma é uma entidade que está diante de uma outra entidade de tal modo que se possa perguntar sobre a conexão entre as duas entidades".

A pergunta que Heidegger fez a Husserl ${ }^{9}$ pode ser feita aqui: que é a subjetividade transcendental ou, na reformulação de Apel, a intersubjetividade transcendental? Não é nada, portanto, é um não-nada e que são os objetos de que tratam as ciências? Também não são nada, um não-nada. Não-nada é o que se pode chamar de determinação mínima, basal, do que a tradição denominou "ente". A Ontologia se pergunta pela forma de ser de cada uma destas entidades e pela totalidade dos entes. Não se trata aqui de abandonar uma postura propriamente filosófica, a postura reflexiva, na direção de uma investigação científica (postura teorética), mas de uma crítica da postura da Pragmática Transcendental através da tematização de todo o espectro daquilo que implica uma reflexão filosófica que pretende ser radical. Apel evitando esta pergunta manifesta um "déficit fundamental" em sua proposta teórica, um déficit de articulação, em primeiro lugar, de uma teoria dos entes, de uma ontologia, porque não pensa o modo de ser da intersubjtividade transcendental (que não é nada, mas algo, ente) como o modo de ser dos objetos (que não são nada, mas algo, entes) de que fala enquanto trabalhados pelas ciências.

Trata-se aqui, portanto, de uma diferença e de uma "relação entre entes" assim de tal modo que outra pergunta se torna irrecusável: Como estão conectadas essas duas formas de ente? Essa conexão última entre os 
entes é a dimensão que, assim, se revela pressuposta por tudo e que nada pressupõe, a dimensão que abarca tudo, diz respeito a tudo que é alguma forma de ente, tudo que não é nada, mas é algo, um não-nada, revela-se como a dimensão absolutamente última que deve ser pensada e explicada. Esta dimensão Heidegger sugeriu denominar de Ser para distinguir de ente. Ser não é ente, ou seja, aquilo que é concebido como polo oposto à intersubjetividade transcendental, mas o que diz respeito a todo e qualquer ente, que abarca tudo, por isso também a intersubjetividade transcendental e a objetividade, ambas são subsumidas na dimensão abrangente.

Nesse contexto, é importante levar em consideração que nada pode ser entendido num duplo sentido. "Num sentido relativo significa a negação de algo determinado mesmo que seja a negação de toda a dimensão dos entes (FDS 108) enquanto que num sentido absoluto significa a negação absolutamente de tudo, a negação do Ser em si" (DE OLIVEIRA, 2019, 326). Quando se diz que um ente é um não-nada, diz-se um nada de ser relativo. Assim, um ser-pedra implica em não ser-cadeira. Esse não-nada aqui é, assim, sempre um não-nada relativo, uma negação relativa à negação da negação de outro ente. A dimensão do Ser é simplesmente pressuposta por todas as dimensões, não pressupõe nada para além de si mesma, nenhuma dimensão mais originária, anterior, que possa constituir seu limite. "Seu limite é o Nada absoluto, mas este não é mais que um conceito vazio" (VIANA, 2019, 327). Ela se refere, então, a tudo que possa ser dito, compreendido, explicado, é o característico último de tudo, de toda e qualquer realidade e, assim, o "dado" oniabrangente, onicompreensivo de uma investigação filosófica. "Assim entendida, a dimensão do Ser é sempre implicitamente presente em toda consideração filosófica dos entes, da totalidade dos entes, do mundo, do universo, da realidade" (DE OLIVEIRA, 2019, 329).

Ser é aquela dimensão que abarca tanto a intersubjetividade transcendental como os objetos. Consequentemente, sua tematização não constitui mais um elemento de uma ontologia, mas no sentido estrito de uma "metafísica originária", porque seu tema é precisamente a dimensão abarcante, aquilo que, então, é o centro de uma investigação filosófica. Isto significa dizer que a Pragmática Transcendental não atingiu a dimensão propriamente última e, assim, é marcada por um déficit não só ontológico, mas também metafísico. 


\section{Notas}

1 Manfredo Araújo de Oliveira, Doutor em Filosofia pela Universidade LudwigMaximilian de Munique, Alemanha. Professor emérito da Universidade Federal do Ceará.

2 As obras de KANT são citadas de acordo com a edição: KANT WERKE da Wissenschaftliche Buchgesellschaft, Darmstadt, 1966.

3 Conforme, Herrero: "Esse modo de argumentação diferencia-se da fundamentação dedutiva de conclusões a partir de premissas que é uma prova direta. O élenchos [...] é uma prova indireta [...] Exemplo clássico de tal prova indireta o oferece Aristóteles quando refuta os filósofos que exigem para o princípio de não-contradição uma prova dedutiva. Esta exigência não tem sentido, pois no fato mesmo de sua argumentação já estão supondo necessariamente o princípio de não-contradição, o que faz com que eles caiam em contradição consigo mesmos" (HERRERO, 1991, 38).

${ }^{4}$ A contraposição fundamental entre Apel e Habermas se radica para Dutra na forma diferente de entender a estrutura lógica do procedimento de fundamentação o que leva Habermas a recusar uma fundamentação última (DUTRA, 1997, 48-66)

${ }^{5}$ A respeito de uma posição crítica em relação a essa proposta de vinculação entre transcendentalidade e intersubjtividade ver: (HÖFFE, 1984, 250-272).

${ }^{6}$ A respeito das objeções feitas à Pragmática Transcendental ver: (KUHLMANN, 1985, 91 ss.).

7 Sobre o sentido da "coisa em si mesma" não há unanimidade entre os intérpretes: (PRAUSS, 1974; RESCHER, 1981). Há outros artigos sobre a temática neste volume: (BONACCINI, 2003).

8 "Kant seria sem dúvida um antirrealista ao afirmar que nós não temos acesso a uma realidade não conceitualizada e, por conseguinte, não há como representar uma realidade independente de nós.... mundo não é aquilo a que a proposição corresponde quando ela é verdadeira, já que somos nós que conformamos o mundo com os nossos próprios conceitos" (LEITE, 1998, 157).

9 Cf. HUSSERL E., Husserliana, 1962, 601-602. Tradução, PUNTEL L.B., FDS, 2015,40-41: "O constituinte não é nulo/nada e, portanto, é algo e é um ente mesmo que não o seja no sentido positivo. Não é possível evitar a questão do modo de Ser do próprio constituinte. Por conseguinte, o problema do Ser diz respeito universalmente tanto ao constituinte quanto ao constituído". 


\section{Referências Bibliográficas}

ALBERT H., Traktat über kritische Vernunft, Tübingen: Mohr Siebeck, 1968; Transzendentale Träumereien, Hamburg: Hoffmann und Campe, 1975.

APEL, Karl-Otto. Der Denkweg von Charles S. Peirce. Eine Einführung in den amerikanischen Pragmatismus, Frankfurt am Main: Shurkamp, 1975a;

APEL, Karl-Otto. The transcendental Conception of LanguageCommunication and the idea of First Philosophy, in: PARRET $\mathrm{H}$. (org.), History of linguistic thought and contemporary linguistics, Berlin/New York: W. de Gruyter, 1975b, 32-61.

APEL, Karl-Otto. Transformation der Philosophie, vol. 1: Sprachanalytik, Semiotik und Hermeneutik, Frankfurt am Main: Suhrkamp, 1976a.

APEL, Karl-Otto. Die Sprache als Thema und als Medium der transzendentalen Reflexion. Zur Gegenwartssituation der Sprachphilosophie, in: Transformation der Philosophie, Vol. 2: Das Apriori der Kommunikationgemeinschaft, Frankfurt am Main: Suhrkamp, 1976b.

APEL, Karl-Otto. Das Problem der philosophischen Letzbegründung im Lichte der Sprachpragmatik, in: KANITSCHNEIDER B. (org.), Sprache und Erkenntnis, Festschrift für Gerhard Frey, Innsbruck: Institut für Sprachwissenschaft der Universität Innsbruck, 1976c.

APEL Karl-Otto., Fallibilismus, Konsenstheorie der Wahrheit und Leztbegründung, in: Philosophie und Begründung, 1987.

APEL, Karl-Otto. Diskurs und Verantwortung. Das Problem des Übergangs zur postkonventionellen Moral, Frankfurt am Main: Suhrkamp, 1988.

APEL, Karl-Otto. Semiótica Filosófica, Editorial Almagestro, Buenos Aires, 1993a.

APEL, Karl-Otto. Fundamentação última não metafísica, in: STEIN E./BONI L.A. de(orgs.), Dialética e Liberdade. Festschrift em homenagem a Carlos Roberto Cirne-Lima, Petrópolis: Vozes, 1993b.

BÖHLER D., Rekonstrutive Pragmatik. Von der Bewußtseinsphilosophie zur Kommunikationsreflexion: Neubegründung der praktischen Wissenschaften und Philosophie, Frankfurt am Main: Suhrkamp, 1985.

BONACCINI J. A., Kant e o problema da coisa em si no Idealismo Alemão: sua atualidade e relevância para a compreensão do problema da Filosofia, Rio de Janeiro/ Natal: Relume Dumará/ UFRN Programa de Pós-Graduação em Filosofia, 2003. 
CARMO A.D.do, Discurso filosófico e a arquitetônica da ética do discurso. Apel versus Habermas, Fortaleza: EdUECE, 2011.

DUTRA D.V., Demonstrar por refutação, in: BOMBASSARO L.C./PAVIANI J.(org.), Filosofia, lógica e existência. Homenagem a Antônio Carlos Kroeff Soares, Caxias do Sul: Educs, 1997.

FENATI R., Realismo e Anti-Realismo, in: MARGUTTI PINTO P. R. et alii (org.), Filosofia Analítica, Pragmatismo e Ciência, Belo Horizonte: Editora UFMG, 1998.

FEYERABEND P., Wider den Methodenzwang. Skizze einer anarchistischen Erkenntnistheorie, Frankfurt am Main: Suhrkamp, 1976.

HEIDEGGER M., Zur Sache des Denkens, Tübingen: Max Niemeyer Verlag, 1969.

HERRERO X., A razão kantiana entre o logos socrático e a pragmática transcendental, in: Síntese Nova Fase 52, 1991, 35-57.

HÖFFE O., Ist die transzendentale Vernuftkritik in der Sprachphilosophie aufgehoben?, in: Phil. Jahrbuch 91 (1984) 250-272.

HÖSLE V., Eine kurze Geschichte der deutschen Philosophie. Rückblick auf den deutschen Geist, München: Verlag C.H. Beck 2013.

KANT I., Kritik der reinen Vernunft, Darmstadt: Wissenschaftliche Buchgesellschaft, 1966.

KRONER R., Von Kant bis Hegel, Tübingen: Mohr J.C., vol. 1 e vol. 2, 1961.

KUHLMANN W., Reflexive Letzbegründung. Untersuchungen zur Transzendentalpragmatik, Freiburg/München: Verlag Karl Albert, 1985.

KRINGS H., Empirie und Apriori. Zum Verhältnis von Transzendentalphilosophie und Sprachpragmatik, in: Neue Hefte für Philosophie, 14 (1978) 57-75.

HUSSERL E., Husserliana. Gesammelte Werke, Vol. IX, 1962, Anlage I.

LEITE P. K. , Realismo e Anti-Realismo na Filosofia Transcendental, in: MARGUTTI PINTO P. R. et alii (org.), Filosofia Analítica, Pragmatismo e Ciência, Belo Horizonte: Editora UFMG, 1998.

McDOWELL J., Putnam on Mind and Meaning, in: Meaning, Knowledge, Reality, Cambridge, Mass./ London: Harvard University Press, 1998.

McDOWELL J., Mente e Mundo, Aparecida: Ideias \& Letras, 2005; 
DE OLIVEIRA, Manfredo Araújo., de, Sobre Fundamentação, Porto Alegre: Edipucrs, 1993;

DE OLIVEIRA, Manfredo Araújo., A metafísica do Ser Primordial. L.B. Puntel e o desafio de repensar a metafísica hoje, São Paulo: Loyola, 2019.

PRAUSS G., Kant und das Problem der Dinge an sich, 3a. ed., Bonn: Bouvier, 1974.

PUNTEL L.B., Estrutura e Ser. Um quadro referencial teórico para uma filosofia sistemática, São Leopoldo: Editora Unisinos, 2008;

PUNTEL L.B., A filosofia como discurso sistemático. Diálogos com Emmanuel Tourpe sobre os fundamentos de uma teoria dos entes, do Ser e do Absoluto, São Leopoldo: Editora Unisinos, 2015.

RESCHER N., On the Status of "Things in Themselves in Kant, in: Synthese 47 (1981)289-299.

RUSSELL B., Mathematical Logic as Based on the Theory of Types, in: American Journal of Mathematics, vol 30 (1908), 222-262.

TUGENDHAT E., Vorlesungen zur Einführung in die sprachanalytische Philosophie, Frankfurt am Main: Suhrkamp, 1976.

VIANA W.C., A filosofia estrutural-sistemática. Uma análise interpretativosistemática, São Leopoldo: Editora Unisinos, 2019.

WITTGENSTEIN L., Tractatus Logico-Philosophicus, São Paulo: Editora da Universidade de São Paulo, 1993. 